\section{0 EDITOR'S CHOICE \\ Reduction of central line infections in Veterans Administration intensive care units: an observational cohort using a central infrastructure to support learning and improvement}

- An additional figure and tables are published online only. To view these files please visit the journal online (http://qualitysafety.bmj. com).

${ }^{1}$ VA Inpatient Evaluation Center, Cincinnati VAMC, Cincinnati, Ohio, USA

${ }^{2}$ VA Health Services Research Center of Excellence, Ann Arbor, Michigan, USA

${ }^{3}$ University of Kansas, Kansas City, Kansas, USA ${ }^{4}$ Division of Pulmonary/ Critical Care/Sleep, University of Cincinnati, Cincinnati, Ohio USA

${ }^{5}$ Department of Internal Medicine, University of Michigan, Michigan, USA

Correspondence to Marta L Render, VA Inpatient Evaluation Center at the Cincinnati VAMC, $205 \mathrm{~W}$ 4th St Suite 800 Cincinnati VAMC, Cincinnati, OH 45220, USA; marta.render@va.gov

The manuscript authors include the VA ICU Clinical Advisory Group who organised regional efforts to reduce CLABSI at each of their medical centres' ICUs.

Accepted 8 March 2011 Published Online First 2 April 2011

\section{ABSTRACT}

Background: Elimination of hospital-acquired infections is an important patient safety goal.

Setting: All 174 medical, cardiac, surgical and mixed Veterans Administration (VA) intensive care units (ICUs). Intervention: A centralised infrastructure (Inpatient Evaluation Center (IPEC)) supported the practice bundle implementation (handwashing, maximal barriers, chlorhexidinegluconate site disinfection, avoidance of femoral catheterisation and timely removal) to reduce central line-associated bloodstream infections (CLABSI). Support included recruiting leadership, benchmarked feedback, learning tools and selective mentoring.

Data collection: Sites recorded the number of CLABSI, line days and audit results of bundle compliance on a secure website.

Analysis: CLABSI rates between years were compared with incidence rate ratios (IRRs) from a Poisson regression and with National Healthcare Safety Network referent rates (standardised infection ratio (SIR)). Pearson's correlation coefficient compared bundle adherence with CLABSI rates. Semi-structured interviews with teams struggling to reduce CLABSI identified common themes.

Results: From 2006 to 2009, CLABSI rates fell (3.8-1.8/ 1000 line days; $\mathrm{p}<0.01)$; as did IRR (2007; 0.83 (95\% Cl 0.73 to 0.94$), 2008 ; 0.65$ (95\% Cl 0.56 to 0.76$)$, 2009; 0.47 (95\% Cl 0.40 to 0.55)). Bundle adherence and CLABSI rates showed strong correlation $(r=0.81)$. VA CLABSI SIR, January to June 2009, was 0.76 (95\% Cl 0.69 to 0.90$)$, and for all FY2009 $0.88(95 \% \mathrm{Cl} 0.80$ to 0.97$)$. Struggling sites lacked a functional team, forcing functions and feedback systems.

Conclusion: Capitalising on a large healthcare system, VA IPEC used strategies applicable to non-federal healthcare systems and communities. Such tactics included measurement through information technology, leadership, learning tools and mentoring.

\section{INTRODUCTION}

The landmark Institute of Medicine report characterised preventable injury as an important and largely ignored problem in healthcare delivery, contributing to mortality and costs. ${ }^{1}$ The Saving 100,000 Lives Campaign of the Institute for Healthcare Improvement (IHI) galvanised efforts to reduce preventable injury. ${ }^{2-5}$ The campaign aimed to reduce two hospital-acquired infections-central line-associated bloodstream infections (CLABSI) and ventilatorassociated pneumonia-by implementing bundles of evidence-based practices. Bundle practices to reduce CLABSI included use of maximal sterile barriers (bed-sized sterile drapes, sterile gown and gloves, cap and mask), chlorhexidine gluconate skin prep, avoidance of femoral sites during insertion and removal of the line once no longer needed. ${ }^{6}{ }^{7}$ Several single and multicentre studies reported reduction in CLABSI after bundle implementation in intensive care units (ICUs). ${ }^{8-12}$ To engage leaders, US payors eliminated a perverse incentive, additional payment for CLABSI. ${ }^{13}$ Recently, the Center for Disease Control (CDC) reported a $17 \%$ reduction in standardised CLABSI rates from January to June 2009 in 17 states with mandatory reporting. ${ }^{14}$

Senior leaders in the Veterans Administration (VA), the largest US healthcare system, agreed to participate in IHI's campaign in 2006. Responsibility for national coordination and measurement of CLABSI was assigned to the director of the VA Inpatient Evaluation Center (IPEC), a new quality infrastructure. 
This paper, following the SQUIRE (Standards for Quality Improvement Reporting Excellence) guidelines $^{15}$ describes the implementation of a practice bundle to reduce CLABSI using infrastructure elements focused on building leadership support, measurement, shared learning, mentoring and teams to move practices.

\section{METHODS}

\section{Project review}

The CLABSI initiative is part of an operational VA ICU quality improvement programme. The proposal to conduct and publish an evaluation of the CLABSI initiative was reviewed and approved by the institutional review board at the University of Cincinnati and the VA ICU clinical advisory group composed of a nurse manager and ICU director from each of the VA's 21 regions.

\section{Setting}

The 174 VA ICUs in 123 hospitals admit $103689 \pm 1156$ patients annually to 1774 beds. The VA has five types of ICUs (cardiac care units, medical intensive care units, medical intensive/cardiac care units, surgical ICUs (caring for predominantly postoperative patients) and mixed units (caring for cardiac, medical and surgical patients)) with four levels of complexity. Level 1 ICUs offer the most complex services and level 4 ICUs have more limited testing and evaluation available. ${ }^{16}$ From electronic data, IPEC reports risk-adjusted mortality and length of stay and process adherence quarterly for all VA ICUs. ${ }^{17} 18$ The characteristics of VA ICUs are described in online supplementary table A.

\section{Intervention}

The national project plan (1) recruited leadership interest, (2) identified strong practices within the VA early and spread their use, (3) created a system for learning, (4) developed a measurement system for CLABSI rates and practice bundle adherence, (5) reported benchmarked CLABSI rates and (6) mentored struggling sites. Local ICUs structured their implementation based on local conditions.

\section{Recruiting leadership and identifying strong practices}

National, regional and hospital leaders agreed to implement the bundle of practices to reduce central line infection rates as part of IHI's Saving 100,000 Lives Campaign in 2006. To recruit mid-level leadership, IPEC programme managers interviewed the ICU nurse managers and infection control practitioners in every VA

VISN 97 FY2009 through Q1 ICU Process Measures

\begin{tabular}{|c|c|c|c|c|c|c|c|c|c|c|c|c|c|}
\hline \multirow{3}{*}{ sim? } & \multicolumn{10}{|c|}{ IPEC ICU } & \multirow{3}{*}{$\begin{array}{l}\text { OQP } \\
\text { AMII }\end{array}$} & \multirow{2}{*}{\multicolumn{2}{|c|}{$\begin{array}{c}\text { RSMR (FY2008) } \\
\text { AMI }\end{array}$}} \\
\hline & \multicolumn{2}{|c|}{$\begin{array}{c}\% \\
\text { Gluc days with } \\
\text { hypo episodes }\end{array}$} & \multirow[b]{2}{*}{$\begin{array}{c}\% \text { Patients } \\
\text { W Mean } \\
\text { Glucose } \\
>180\end{array}$} & \multicolumn{3}{|c|}{ DVT-prophylaxis } & \multicolumn{2}{|c|}{ Throughput } & \multicolumn{2}{|c|}{ Infection } & & & \\
\hline & $\begin{array}{r}\leq 45 \\
\mathrm{mg} \mathrm{dl}\end{array}$ & $\begin{array}{l}<60 \\
\mathrm{mg} \mathrm{dl}\end{array}$ & & $\begin{array}{l}\text { Mech } \\
\text { vent }\end{array}$ & $\begin{array}{c}\text { Non } \\
\text { Op }\end{array}$ & Op & $\begin{array}{l}\text { OME } \\
\text { LOS }\end{array}$ & LOS & $\begin{array}{c}\text { CLABSI } \\
\text { Rate }\end{array}$ & VAP Rate & & $\begin{array}{l}\text { IPEC } \\
\text { acute } \\
\text { care }\end{array}$ & $\begin{array}{l}\text { Hospital } \\
\text { referred } \\
\text { region }\end{array}$ \\
\hline \multicolumn{14}{|l|}{ National aggregates } \\
\hline Facility level 15 th \%tile & 0.5 & 1.8 & 10.2 & 61.4 & 59.3 & 57.1 & -0.72 & 2.18 & 0.00 & 0.00 & & 14.68 & 15.76 \\
\hline Facility level mean & 1.4 & 3.6 & 16.8 & 76.0 & 70.9 & 81.7 & -0.06 & 2.87 & 1.84 & 2.83 & & 14.91 & 16.09 \\
\hline Facility level 85th \%tile & 2.3 & 5.3 & 23.0 & 96.0 & 83.3 & 100.0 & 0.63 & 3.58 & 4.72 & 7.04 & & 15.13 & 16.46 \\
\hline \multicolumn{14}{|l|}{ National aggregates } \\
\hline Site 1 & 1.6 & 5.3 & 23.0 & 78.9 & 83.3 & 100.0 & -0.99 & 2.15 & 1.31 & 12.12 & & 14.68 & 16.55 \\
\hline Site 2 & 0.5 & 1.0 & 10.2 & 80.0 & 60.6 & 100.0 & 0.50 & 3.18 & 0.00 & 3.18 & $\checkmark$ & 15.52 & 16.23 \\
\hline Site 3 & 1.0 & 4.7 & 21.5 & 79.4 & 59.3 & 45.5 & -0.01 & 2.91 & 6.61 & 0.00 & $\star$ & 15.08 & 16.19 \\
\hline Site 4 & 3.1 & 5.0 & 11.9 & 59.0 & 63.2 & 75.0 & 0.14 & 3.36 & 0.00 & 7.19 & $\checkmark$ & 15.23 & 16.72 \\
\hline Site 5 & 1.0 & 3.1 & 22.0 & 89.5 & 61.4 & 50.0 & -0.53 & 2.27 & 0.00 & 0.00 & $\checkmark$ & 14.77 & 16.2 \\
\hline Site 6 & 0.5 & 3.0 & 13.8 & 74.1 & 70.6 & 86.7 & -0.85 & 2.59 & 0.00 & 0.00 & $\checkmark$ & 14.83 & 15.94 \\
\hline Site 7 & 2.0 & 4.4 & 13.5 & 61.4 & 75.0 & 100.0 & 0.36 & 3.47 & 1.98 & 2.49 & $\checkmark$ & 14.73 & 16.18 \\
\hline Site 8 & 0.8 & 1.3 & 13.3 & 80.0 & \begin{tabular}{|l|}
50.7 \\
\end{tabular} & 41.2 & \begin{tabular}{l|l|} 
\\
\end{tabular} & 2.20 & 2.49 & 5.95 & & 14.86 & 16.1 \\
\hline Site 9 & 0.6 & 2.6 & 23.8 & 91.7 & 86.4 & & 0.98 & 4.22 & 0.00 & 0.00 & $\checkmark$ & 14.62 & 16.18 \\
\hline
\end{tabular}

Figure 1 Intensive care unit (ICU) process page in quarterly dashboard, where aggregated national results are presented (mean, 15th and 85th percentile). Process page tracks CLABSI and ventilator associated pneumonia rates, it also tracks hypoglycaemia and hyperglycaemia, pharmacologic prophylaxis to prevent deep venous thrombosis and throughput. 
ICU, reviewing existing practices to reduce CLABSI and CLABSI rates. These interviews identified early successful sites.

An ICU dashboard updates the leadership regarding progress of their ICUs in reducing CLABSI rates compared with national rates (figure 1). The IPEC director identified progress or problems in reducing CLABSI and strategies to jumpstart success in biannual regional conference calls attended by regional and hospital directors and chief medical officers and ICU managers. The annual executive leadership contract and performance contracts of some ICU managers included reduction in CLABSI rates in 2008.

\section{Creating learning}

The national project began with a 2-hour web-based conference call (agenda - online supplementary table B). Senior VA leadership confirmed the initiative's importance; experts reviewed CLABSI and the evidence for prevention of CLABSI. ICU teams that had already successfully reduced their CLABSI infection rates presented their experience, emphasising five facilitators: (1) a physician champion, (2) use of central line cart and (3) checklist during line insertion as a forcing function, (4) addition of a daily ICU goal sheet during physician rounds as a memory aid for central line removal, (5) and feedback to frontline nurses and doctors about their CLABSI rates and bundle adherence. Finally, the conference call highlighted an improvement in approach that used multiple small tests of change asking always "what can we do by next Tuesday'.

A web-based toolbox shared tools from ICUs that had reduced their CLABSI rates. These tools included CDC definitions, case scenarios to test understanding of the definitions, measurement tools, an annotated bibliography, powerpoint slides adaptable for local presentations, learning modules with continuing education units (CEUs), depiction of contents and organisation of a line cart, examples of daily goal sheets and policies and procedures. Some ICUs mandated learning module completion, others made it available with free CEU as an incentive.

\section{Mentoring}

Twelve months after the kick-off, IPEC programme managers invited five to six ICUs with either the highest CLABSI rates or absolute numbers of infections to be mentored. Initial semi-structured interviews with each site focused on use of facilitators (team members, established goal for initiative, physician champion, feedback system to front line staff and to local leadership, use of forcing functions, availability of supplies needed for implementation) identified in the literature and improvement method (online supplementary table $\mathrm{C}$ ). From the interview, programme managers and the sites projected a series of Plan-Do-Study-Act (PDSA) cycles. The progress towards implementation of next step was assessed with monthly calls. In a qualitative analysis, two investigators (MLR, RH) reviewed data from the initial structured interviews and notes from the calls for common themes.

\section{Planning the study of the intervention}

This was an observational quality improvement project where adherence to the CLABSI bundle elements and CLABSI rates were tracked monthly across all ICUs in the VA.

\section{Measures/definitions}

CDC definitions were used (table 1). ${ }^{19}$

\section{Data collection}

Although central line infection rates and adherence to the evidence-based practice bundle was not recorded electronically when the national CLABSI project began, local VA ICUs did collect central line days and bloodstream infections. IPEC created a data management website, operational in March/April 2006 (online supplementary figure A), where ICUs entered monthly (1) line days, (2) number of CLABSI and (3) the number of audits or checklists completed during central line insertion and

Table 1 Definitions of central line-associated bloodstream infections (CLABSI)

\begin{tabular}{ll}
\hline Data element & Definition \\
\hline Central line & Terminates at or near the heart or in a great vessel. \\
CLABSI infection rate & $\begin{array}{l}\text { Number of CLABSI divided by the number of device days multiplied by 1000. For hospitals } \\
\text { with }<750 \text { line days, the number of months since the last infection is reported. }\end{array}$ \\
Laboratory confirmed & $\begin{array}{l}\text { When a patient has or had a central line within the past } 48 \mathrm{~h} \text { and either a recognised } \\
\text { pathogen is grown in one or more blood cultures in the absence of another source for that } \\
\text { pLABSI infection }\end{array}$ \\
& $\begin{array}{l}\text { pathogen or the patient has clinical signs of infection (hypotension, fever, chills) not related } \\
\text { to another site of infection and grows a skin pathogen from at least two blood cultures. }\end{array}$ \\
Central line day & Counted for each patient who has one or more central lines in place. \\
Central line utilisation rate & Number of line days divided by the number of patient days.
\end{tabular}


Table 2 Central line-associated bloodstream infections and rates and practice adherence stratified by year and ICU characteristics

\begin{tabular}{|c|c|c|c|c|}
\hline All VA ICUs & FY2006 & FY2007 & FY2008 & FY2009 \\
\hline CLABSI infection rate & 3.85 & 3.18 & 2.50 & 1.80 \\
\hline Line days & 177058 & 214604 & 216818 & 224693 \\
\hline CLABSI infections & 681 & 683 & 543 & 404 \\
\hline CLABSI audits & 7822 & 13315 & 13554 & 16130 \\
\hline Central line utilisation & 31.8 & 42.2 & 42.9 & 39.2 \\
\hline \multicolumn{5}{|l|}{ Practice adherence (began April 2006) } \\
\hline Hand hygiene & 95.4 & 97 & 98.2 & 98.2 \\
\hline Cap worn & 91.6 & 95.4 & 97 & 97.8 \\
\hline Bed-sized drape & 88.1 & 93.7 & 95.8 & 97.1 \\
\hline Chlorhexidinegluconate skin prep & 93.5 & 97.5 & 98.5 & 98.4 \\
\hline Femoral site & 18.4 & 17.1 & 16.2 & 12.2 \\
\hline Sterile gloves worn & 96.9 & 98.2 & 99.1 & 98.6 \\
\hline Sterile gown worn & 95.8 & 97 & 98.2 & 98.3 \\
\hline \multicolumn{5}{|l|}{ By level of complexity of ICU } \\
\hline \multicolumn{5}{|l|}{ CLABSI infection rate (year) } \\
\hline Level 1 & 3.79 & 3.14 & 2.61 & 1.80 \\
\hline Level 2 & 4.37 & 3.78 & 2.42 & 2.11 \\
\hline Level 3 & 3.82 & 2.89 & 2.07 & 1.40 \\
\hline Level 4 & 1.96 & 1.63 & 0.64 & 1.55 \\
\hline \multicolumn{5}{|l|}{ Number of line days } \\
\hline Level 1 & 132790 & 159351 & 164321 & 165221 \\
\hline Level 2 & 24952 & 29373 & 28120 & 32758 \\
\hline Level 3 & 16767 & 22821 & 21247 & 23489 \\
\hline Level 4 & 2549 & 3059 & 3130 & 3225 \\
\hline \multicolumn{5}{|l|}{ Number of CLABSI infections } \\
\hline Level 1 & 503 & 501 & 429 & 297 \\
\hline Level 2 & 109 & 111 & 68 & 69 \\
\hline Level 3 & 64 & 66 & 44 & 33 \\
\hline Level 4 & 5 & 5 & 2 & 5 \\
\hline \multicolumn{5}{|l|}{ Number of audits } \\
\hline Level 1 & 4919 & 8498 & 8887 & 10826 \\
\hline Level 2 & 1349 & 2499 & 2222 & 2575 \\
\hline Level 3 & 1348 & 1903 & 2054 & 2290 \\
\hline Level 4 & 206 & 415 & 391 & 439 \\
\hline \multicolumn{5}{|l|}{ By type of ICU } \\
\hline \multicolumn{5}{|l|}{ CLABSI infection rate (year) } \\
\hline Mixed ICU & 3.65 & 2.82 & 2.42 & 1.68 \\
\hline $\mathrm{CCU}$ & 4.53 & 2.37 & 1.89 & 1.68 \\
\hline MICU & 4.24 & 3.85 & 2.71 & 2.01 \\
\hline SICU & 3.40 & 2.91 & 2.37 & 1.87 \\
\hline MICU/CCU & 4.58 & 4.04 & 2.85 & 1.82 \\
\hline \multicolumn{5}{|l|}{ Number of line days } \\
\hline Mixed ICU & 53393 & 70302 & 67781 & 77251 \\
\hline $\mathrm{CCU}$ & 5519 & 8447 & 8975 & 8911 \\
\hline MICU & 18397 & 20764 & 21062 & 18403 \\
\hline SICU & 62870 & 70548 & 71010 & 68931 \\
\hline MICU/CCU & 36879 & 44543 & 47990 & 51197 \\
\hline \multicolumn{5}{|l|}{ Number of CLABSI infections } \\
\hline Mixed ICU & 195 & 198 & 164 & 130 \\
\hline $\mathrm{CCU}$ & 25 & 20 & 17 & 15 \\
\hline MICU & 78 & 80 & 57 & 37 \\
\hline SICU & 214 & 205 & 168 & 129 \\
\hline MICU/CCU & 169 & 180 & 137 & 93 \\
\hline \multicolumn{5}{|l|}{ Number of audits } \\
\hline Mixed ICU & 2999 & 5128 & 4874 & 5387 \\
\hline $\mathrm{CCU}$ & 296 & 591 & 642 & 895 \\
\hline
\end{tabular}


Table 2 Continued

\begin{tabular}{clllr}
\hline All VA ICUs & FY2006 & FY2007 & FY2008 & FY2009 \\
\hline MICU & 882 & 1269 & 1424 & 1894 \\
SICU & 1876 & 2904 & 2987 & 3987 \\
MICU/CCU & 1769 & 3423 & 3627 & 3967 \\
\hline
\end{tabular}

CCU, cardiac care unit; CLABSI, central line-associated bloodstream infections; ICU, intensive care unit; level, the complexity of ICU services available; MICU, medical intensive care unit; MICU/CCU, medical intensive/cardiac care unit; SICU, surgical intensive care unit; VA, Veterans Administration.

from those checklists (4) the number of times individual bundle practices were used including femoral location. Data entry into the website required completion of a learning session and a test-correctly identifying CLABSI infections in case scenarios based on CDC definitions. ${ }^{19}$ The programme included audits because the audit tool teaches critical bundle elements and facilitates communication about bundle adherence between team members.

\section{Statistical analysis}

Analysis of variance ( $\mathrm{p}$ value $<0.05$ significant) compared annual counts of central line infections, line days, CLABSI rates (infections/1000 line days) and adherence with the central line bundle. Pearson's correlation coefficient assessed the relationship of CLABSI rates to bundle adherence. Incidence rate ratios (IRR, an estimate of the rate of disease development) compared CLABSI infections rates between each fiscal year and the reference year 2006 using a Poisson regression (repeated measures generalised estimating equation (GEE)). A standardised infection ratio (SIR) compared observed to predicted infections (calculated by multiplying the line days for each type of unit by the CLABSI rates of a referent ICU specific population in the National Healthcare Safety Network (NHSN) from 2006 to 2008). ${ }^{20}$

\section{RESULTS}

\section{Intensive care unit central line data}

This report covers 833172 central line days (208 294/ year) reported from 2006 through the fourth quarter of 2009 representing 8352 ICU months (2076 ICU months annually). ICUs averaged $1068 \pm 844$ central line days annually (range 74-3682; table 2). Central lines utilisation was $40.5 \%$ in $2007,41.5 \%$ in 2008 and $43.3 \%$ in 2009, somewhat less than the 52 line days/patient days reported by the NHSN in medical surgical units. ${ }^{21}$

\section{Adherence to evidence-based practices}

VA ICUs audited insertion of 7822 central lines in the last two quarters of 2006, increasing to 16130 in 2009 as the improvement efforts spread. Central lines placed outside of the ICU (operating room, emergency room, acute care wards) were not audited, though CLABSI in the ICU from those lines were included. The increase in composite adherence to practice bundle from $85 \%$ to 98\% (second quarter of 2006, when the data management website first became available; 4 months following the kick-off call, to 2009) had a strong inverse correlation $(\mathrm{R}=-0.81$ ) with CLABSI rates (figure 2).

\section{Infection rates and infections}

The number of CLABSI decreased by 140 cases (from 683 to $543, \mathrm{p} \leq 0.01$ ) in 2008 compared with 2007 , and by 139 cases (from 543 to $404, \mathrm{p}<0.01$ ) in 2009 compared with 2008. The national CLABSI rate/1000 line days decreased from 3.85/1000 line days in 2006 to 1.8/1000 line days in 2009. CLABSI rates fell in all types and levels of ICUs (table 2). Fifty of 174 ICUs $(28.7 \%$ ) reported a CLABSI rate of 0 for 2009; 74 ICUs $(40.8 \%)$ reported a rate of 0 in the final 6 months of 2009. ICUs with CLABSI rates at 0 for 2 years were more often small delivering less complicated care (level 3 or 4, 21/29; $72.4 \%$ ). IRR from the Poisson regression (repeated measures GEE) found years 2007-2009 compared to

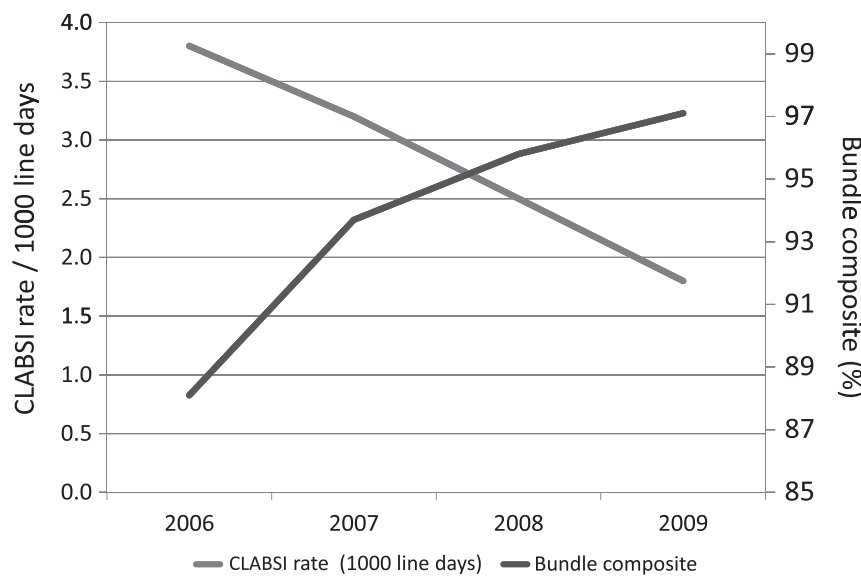

Figure 2 Reduction in CLABSI rate and improvement in adherence to bundle practices. The elements in the bundle practice included handwashing, use of maximal sterile barriers (bed-sized sterile drapes, sterile gown and gloves, cap and mask), chlorhexidinegluconate skin prep, avoidance of femoral site during insertion and removal of the line once no longer needed. 
Table 3 Incidence rate ratios from Poisson regression

\begin{tabular}{|c|c|c|c|c|c|c|}
\hline \multirow[b]{2}{*}{ Fiscal year } & \multicolumn{4}{|c|}{ Summary statistics-CLABSI rate } & \multicolumn{2}{|l|}{ Time } \\
\hline & Mean & Median & $25 \%$ & $75 \%$ & IRR (95\% CI) & p Value \\
\hline 2006 & 3.84 & 3.20 & 0.70 & 5.70 & Reference & \\
\hline 2007 & 3.19 & 2.65 & 1.20 & 4.50 & $0.83(0.73$ to 0.94$)$ & 0.0033 \\
\hline 2008 & 2.44 & 2.10 & 0.50 & 3.50 & $0.65(0.56$ to 0.76$)$ & $<0.0001$ \\
\hline 2009 & 1.85 & 1.20 & 0.00 & 2.50 & $0.47(0.40$ to 0.55$)$ & $<0.0001$ \\
\hline
\end{tabular}

IRR, incidence rate ratio.

2006 significantly associated with CLABSI rates $(\mathrm{p}<0.001$, table 3).

The VA SIR for fiscal year 2009 and for the first 6 months of calendar year 2009 was significantly lower than the NHSN 2006-2008 referent rates $(0.88$ (95\% CI 0.80 to 0.97 ); table 4 and 0.76 (95\% CI 0.69 to 0.90$)$, respectively; online supplementary table $\mathrm{D})$.

\section{Effectiveness of intervention strategies}

Participation by local ICUs in the web-based national conferences, measured by number of telephone lines in use during the call was high for the kick-off call (215 lines), and the follow-up call in 4 months (185 lines). During the project, 2016/40503 (48\%) of Full Time Employee Equivalent nurses completed the CLABSI learning modules.

Four out of six hospitals with the highest numbers and rates of infections volunteered to participate in mentoring. Over a year, infection rates of mentored sites decreased 53\%, from 7.7/1000 line days in 2007 to 3.6/ 1000 line days in 2008; and 1.1/1000 line days in 2009. Common themes from qualitative analysis of initial semistructured interviews included a poorly organised team, lack of a physician champion, failure to set a goal, limited or no feedback to clinicians regarding the unit's infection rates and lack of forcing functions (line carts, checklists, etc.).

\section{DISCUSSION}

This paper reports a reduction in CLABSI in the largest healthcare system in the USA. The infrastructure and systematic approach used in this effort can be translated to improvement projects in other large healthcare systems, states and communities as well as VA ICUs. The qualitative analysis of struggling sites supports the value of using a variety of strategies in improvement efforts.

The SIR for the VA CLABSI in 2009 is similar to referent rates reported by the $\mathrm{NHSN}^{21}$ and those reported by Missouri, ${ }^{22}$ Pennsylvannia, ${ }^{23}$ New York $^{24}$ and Colorado. ${ }^{25}$ The VA SIR (0.77) for the first 6 months of 2009 is lower than the NHSN SIR of 0.83 in 17 states with mandatory CLABSI reporting. Since the NSHN rate for the 17 states is drawn from an incomplete sample of hospitals (range $32-100 \%$ by state), selection bias may overestimate improvement in these states. In contrast, the VA SIR represents a $100 \%$ sample. VA ICUs, like others nationally, will be challenged to meet the 5-year goal of US Health Human Services to reduce CLABSI by $75 \%$ (SIR of 0.25 ), translating to CLABSI rates by type of ICU between 0.37 and 0.56/1000 line days. We found the goal of zero infections/line days achievable in ICUs with limited missions, but sustaining zero in large complex ICUs may be associated with patient factors

Table 4 Standardised infection rate ratio comparing CLABSI in VA ICUs with referent rates from National Healthcare Safety Network fiscal year 2009

\begin{tabular}{|c|c|c|c|c|c|c|c|c|c|}
\hline \multirow[b]{2}{*}{ ICU } & \multirow[b]{2}{*}{ NHSN group } & \multicolumn{5}{|c|}{ Observed CLABSI rates in FY2009 } & \multicolumn{3}{|c|}{ NHSN CLABSI rates 2006-2008 } \\
\hline & & CLABSI & $\begin{array}{l}\text { Line } \\
\text { days }\end{array}$ & $\begin{array}{l}\text { CLABSI } \\
\text { rate }\end{array}$ & $\begin{array}{l}\text { Pred } \\
\text { CLABSI }\end{array}$ & SIR & $\begin{array}{l}\text { No. of } \\
\text { CLABSI }\end{array}$ & $\begin{array}{l}\text { No. of line } \\
\text { days }\end{array}$ & $\begin{array}{l}\text { CLABSI } \\
\text { rate }\end{array}$ \\
\hline Mixed LVL 1 & $\begin{array}{l}\text { Medical surgical } \\
\text { teaching }\end{array}$ & 59 & 33568 & 1.76 & 70.76 & 0.83 & 1474 & 699300 & 2.11 \\
\hline $\begin{array}{l}\text { Mixed LVL } \\
2,3,4\end{array}$ & $\begin{array}{l}\text { Medical surgical } \\
<15\end{array}$ & 71 & 43683 & 1.63 & 65.34 & 1.09 & 1130 & 755437 & 1.50 \\
\hline Medical & Medical ICU & 37 & 18403 & 2.01 & 42.34 & 0.87 & 2097 & 911476 & 2.30 \\
\hline Surgical & Surgical ICU & 127 & 68953 & 1.84 & 158.97 & 0.80 & 1683 & 729989 & 2.31 \\
\hline Medical CCU & $\mathrm{Med} / \mathrm{CCU}$ & 94 & 51175 & 1.84 & 102.72 & 0.92 & 876 & 436409 & 2.01 \\
\hline VA overall & & 388 & 215782 & 1.80 & 440.13 & 0.88 & & & \\
\hline
\end{tabular}

LVL, level; NHSN, National Healthcare Safety Network; CLABSI, central line-associated bloodstream infections; CLABSI rate, CLABSI divided by line days multiplied by 1000; Pred CLABSI, predicted VA CLABSI rates; NHSN CLABSI rate divided by 1000 times VA line days; SIR, standardised infection rate (observed number of CLABSI divided by the predicted CLABSI). 
such as the duration of line placement, rather than bundle adherence on insertion.

Three multicentre projects in the USA have reported reduction in CLABSI. ${ }^{11} 1226$ The largest report to date, the Keystone project, includes 103 ICUs in 67 Michigan hospitals. ${ }^{12}$ Like the Keystone project, the VA IPEC programme includes multiple targets for ICU implementation (ventilator-associated pneumonia bundle, use of daily goal sheet, increased use of prophylaxis for deep venous thrombosis, glycaemic control). The VA project differed from Keystone project in scope, implementation pathway and data collection. First, the VA project involved ICUs geographically distributed across the USA compared with a single state in the Keystone project. Second, the Keystone project used a collaborative pathway (face to face biannual meetings, conference calls with each site twice a month). In contrast, the VA project used a more streamlined model, taking advantage of its size, to provide benchmarks by type of ICU, building a toolbox that shared tools from successful sites and mentoring a minority of ICUs. This approach was likely facilitated by a longstanding culture of performance measurement and quality improvement and clear lines of authority within the VA. Third, the VA project reports both process and outcomes and includes a brief qualitative analysis of common facilitators to reducing CLABSI.

The study is limited in that all the data are selfreported. Safeguards that improved the data accuracy included test cases to assure understanding of the CDC definitions, conference calls with infection control practitioners and an open help desk for questions. The spikes observed monthly in ICU infection rates as the processes for sustaining low infection rates degraded suggest that the self-report is representative. A 2005 survey which found VA hospitals' reported use of CLABSI bundle elements more often than non-VA hospitals supports adherence results. ${ }^{27}$ Several factors argue against a temporal trend in infection rates accounting for the reduction in CLABSI, unrelated to the intervention. First, the economic incentive, elimination of additional payment for CLABSI didn't affect VA hospitals. Second, the rate of change mirrors the stepwise implementation of interventions - the national kick-off call, feedback, mentoring and addition of the CLABSI rates to executive performance contracts. Third, the timeframe matches that of the Keystone project adjusting for the differences in size. Healthcare systems or communities with different organisational cultures might need to adapt these tactics.

The VA quality infrastructure in the ICU capitalises on the electronic medical record to build quality indicators for ICU report cards. ${ }^{28} 29$ The VA CLABSI initiative applied principles from high performing microsystems and organisations ${ }^{30}$ : (1) engaging multiple levels of leadership, (2) support of the microsystem (measurement, benchmarking, tools, policies/procedure samples), (3) education/training (learning modules with CEU), (4) interdependence (daily goal sheets), (5) process improvement (CLABSI project), (6) performance results (report cards and review by regional and local leadership) and (7) information technology (rollup of local data, dissemination of results). VA ICUs reduced the CLABSI across all types and levels of ICUs. This model can likely be used to support improvement goals in the private sector within large healthcare systems, states or community improvement projects.

Funding This work was supported by the Veterans Health Administration as part of its quality improvement mission.

\section{Competing interests None.}

Ethics approval This study was conducted with the approval of the University of Cincinnati.

Contributors The authors include the VA Intensive Care Advisory Group whose members implemented the project in each region.

Provenance and peer review Not commissioned; externally peer reviewed

\section{REFERENCES}

1. Shojania KG, Duncan BW, McDonald KM, et al. Making Health Care Safer: A Critical Analysis of Patient Safety Practices. Rockville, Maryland: AHRQ Publication No. 01-E058, 2001.

2. Berwick DM, Calkins DR, McCannon CJ, et al. The 100,000 lives campaign: setting a goal and deadline for improving healthcare quality. JAMA 2006;295:324-7.

3. Raad II, Bodey GP. Infectious complications of indwelling vascular catheters. Clin Infect Dis 1992;15:197-208.

4. Weinstein MP, Towns ML, Quartey SM, et al. The clinical significance of positive blood cultures in the 1990s: a prospective comprehensive evaluation of the microbiology, epidemiology, and outcome of bacteremia and fungemia in adults. Clin Infect Dis 1997;24:584-602.

5. Soufir L, Timsit JF, Mahe C, et al. Attributable morbidity and mortality of catheter-related septicemia in critically ill patients: a matched, risk-adjusted, cohort study. Infect Control Hosp Epidemiol 1999;20:396-401.

6. Saint S, Veentra DL, Lipsky BA. The clinical and economic consequences of nosocomial central venous catheter-related infection: are antimicrobial catheters useful? Infect Control Hosp Epidemiol 2000;21:375-80.

7. Chaiyakunapruk N, Veenstra DL, Lipsky BA, et al. Chlorhexidine compared with povidone-iodine solution for vascular catheter-site care: a meta-analysis. Ann Intern Med 2002;136:792-801.

8. Curtis JR, Cook DJ, Wall RJ, et al. Intensive care unit quality improvement: a "how-to" guide for the interdisciplinary team. Crit Care Med 2006;34:211-18.

9. Koll BS, Straub TA, Jalon HS, et al. The CLABs collaborative: a regionwide effort to improve the quality of care in hospitals. Jt Comm J Qual Patient Saf 2008;34:713-23.

10. Galpern D, Guerrero A, Tu A, et al. Effectiveness of a central line bundle campaign on line-associated infections in the intensive care unit. Surgery 2008;144:492-5.

11. Render ML, Brungs S, Kotagal, et al. Evidence-based practice to reduce central line infections. Jt Comm J Qual Patient Saf 2006;32:253-60.

12. Pronovost $\mathrm{P}$, Needham $\mathrm{D}$, Berenholtz $\mathrm{S}$, et al. An intervention to decrease catheter-related bloodstream infections in the ICU. $N$ Engl J Med 2006;355:2725-32.

13. CMS. Hospital Acquired Conditions Fact Sheet, 2008. http://www. cms.hhs.gov/HospitalAcqCond/02_Statute_Regulations_Program Instructions.asp\#TopOfPage (accessed 24 Apr 2009).

14. Center for Disease Control. First State Specific HealthcareAssociated Infections Summary Data Report. http://www.cdc.gov/hai/ pdfs/stateplans/SIR_05_25_2010.pdf (accessed 1 Aug 2010).

15. Sox HC. Improving the quality of reporting studies of quality improvement: the SQUIRE guidelines. Ann Intern Med 2008;149:683. 
16. Almenoff $\mathrm{P}$, Sales $\mathrm{A}$, Rounds $\mathrm{S}$, et al. Intensive care services in the Veterans Health Administration. Chest 2007;132: 1455-62.

17. Render ML, Kim HM, Deddens J, et al. Variation in outcomes in Veterans Affairs intensive care units with a computerized severity measure. Crit Care Med 2005;33:930-9.

18. Render ML, Deddens J, Freyberg R, et al. Veterans Affairs intensive care unit risk adjustment model: validation, updating, recalibration. Crit Care Med 2008;36:1031-42.

19. Horan TC, Andrus M, Dudeck MA. CDC/NHSN surveillance definition of health care-associated infection and criteria for specific types of infections in the acute care setting. Am J Infect Control 2008;36:309-32

20. Gustafson TL. Practical risk-adjusted quality control charts for infection control. Am J Infect Control 2000;28:406-14.

21. Edwards JR, Peterson KD, Andrus ML, et al. National Healthcare Safety Network (NHSN) Report, data summary for 2006 through 2007, issued November 2008. Am J Infect Control 2008;36:609-26.

22. Hospital Acquired Infections in Missouri. 2008. http://www.dhss.mo. gov/HAl/main.php (accessed 31 Aug 2009).
23. Hospital Acquired Infections in Pennsylvannia. 2007. http://www. phc4.org/reports/hai (accessed 31 Aug 2009).

24. Hospital Acquired Infections in New York State. 2008. http://www. health.state.ny.us/statistics/facilities/hospital/hospital_acquired_ infections

25. State of Colorado Status Report on the Health Facility Acquired Infections Disclosure Initiative. 2009. http://www.cdphe.state.co.us/ hf/PatientSafety (accessed 27 Dec 2009).

26. Warren DK, Cosgrove SE, Diekema DJ, et al. A multicenter intervention to prevent catheter-associated bloodstream infections. Infect Control Hosp Epidemiol 2006;27:662-9.

27. Krein SL, Hofer TP, Kowalski CP, et al. Use of central venous catheter-related bloodstream infection prevention practices by US hospitals. Mayo Clin Proc 2007;82:672-8.

28. Berenholtz SM, Dorman $\mathrm{T}, \mathrm{Ngo} \mathrm{K}$, et al. Qualitative review of intensive care unit quality indicators. J Crit Care 2002;17:1-12.

29. McMillan TR, Hyzy RC. Bringing quality improvement into the intensive care unit. Crit Care Med 2007;35(Suppl 2):S59-65.

30. Foster TC, Johnson JK, Nelson EC, et al. Using a Malcolm Baldrige framework to understand high-performing clinical microsystems. Qual Saf Health Care 2007;16:334-41.

\section{JOURNAL OF} Family Planning and Reproductive Health Care

BMJ Group are proud to announce that they will be publishing the Journal of Family Planning and Reproductive Health Care on behalf of the Faculty of Sexual and Reproductive Healthcare from 2011.

\section{A fresh perspective}

Our aim is to further develop this highly regarded title, which publishes quality research and information relevant to clinical care, service delivery, training and education in the field of contraception and reproductive/sexual health.

The journal has an exciting new look and JFPRHC Online has been enhanced to provide useful resources and interactive features such as:
- Editor's choices
Email alerts
- Top 10 articles
Online archive
- Podcasts BMJIJournals

Visit jfprhc.bmj.com to view the new site and to register for a

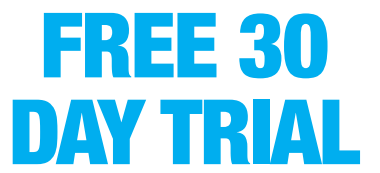
DAY TRIAL 